NASA Technical Memorandum 107093

\title{
Human Exploration and Settlement of the Moon Using LUNOX-Augmented NTR Propulsion
}

Stanley K. Borowski

Lewis Research Center

Cleveland, Ohio

Donald W. Culver and Melvin J. Bulman

GenCorp Aerojet

Sacramento, California

Prepared for the

12th Symposium on Space Nuclear Power and Propulsion cosponsored by BMDO, NASA, DOE, and USAF

Albuquerque, New Mexico, January 8-12, 1995

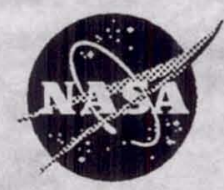

National Aeronautics and

Space Administration 


\title{
HॄUMAN EXPLORATION AND SETTLEMENT OF THE MOON USING LUNOX-AUGMENTED NTR PROPULSION
}

\author{
Stanley K. Borowski \\ NASA Lewis Research Center \\ 21000 Brookpark Road \\ Cleveland, $\mathrm{OH} 44135$ \\ (216) $977-7091$
}

\author{
Donald W. Culver and Melvin J. Bulman \\ GenCorp Aerojet \\ P.O. Box 13222 \\ Sacramento, CA 95813-6000 \\ (910) 355-2083 and -3451
}

\begin{abstract}
An innovative trimodal nuclear thermal rocket (NTR) concept is described which combines conventional liquid hydrogen $\left(\mathrm{LH}_{2}\right)$-cooled NTR, Brayton cycle power generation and supersonic combustion ramjet (scramjet) technologies. Known as the liquid oxygen (LOX)-augmented NTR (LANTR), this concept utilizes the large divergent section of the NTR nozzle as an "afterburner" into which LOX is injected and supersonically combusted with nuclear preheated hydrogen emerging from the LANTR's choked sonic throat-"scramjet propulsion in reverse." By varying the oxygen-to-hydrogen mixture ratio (MR), the LANTR can operate over a wide range of thrust and specific impulse (Isp) values while the reactor core power level remains relatively constant. As the MR varies from zero to seven, the thrust-to-weight ratio for a 15 thousand pound force (klbf) NTR increases by $440 \%$--from 3 to 13-while the Isp decreases by only $45 \%$--from 940 to 515 seconds. This thrust augmentation feature of the LANTR means that "big engine" performance can be obtained using smaller, more affordable, easier to test NTR engines. "Reoxidizing" the bipropellant LANTR system in low lunar orbit (LLO) with high density "lunar-derived" LOX (LUNOX) enables a reusable, reduced size and mass lunar transfer vehicle (LTV) which can be deployed and resupplied using two $66 \mathrm{t}$-class Shuttle-derived launch vehicles. The reusable LANTR can also transport 200 to $300 \%$ more payload on each piloted round trip mission than an expendable "all $\mathrm{LH}_{2}{ }^{n}$ NTR system. As initial outposts grow to eventual lunar settlements and LUNOX production capacity increases, the LANTR concept can also enable a rapid "commuter" shuttle capable of 36 to 24 hour "one way" trips to the Moon and back with reasonable size vehicles and initial mass in low Earth orbit (IMLEO) requirements.
\end{abstract}

\section{INTRODUCTION}

Various lunar mission profiles and space transportation system (LTS) options have been examined over the last seven years. In its “90 Day Study Report" (NASA 1989), NASA selected a lunar orbit rendezvous (LOR) mission profile and a LTS consisting of a space-based LTV operating between low Earth orbit (LEO) and LLO, and a lunar landing vehicle (LLV) for transportation from LLO to the lunar surface and back (Priest and Woodcock 1990). The partially reusable LTV employed aerobraking for capture into LEO and was refurbished after each mission at a LEO transportation node assumed to be a growth version of the space station. A cargo version of the current Space Shuttle (Shuttle C) or an "in-line" Shuttle-derived vehicle (SDV) was also baselined for Earth-to-orbit launch (see Figure 1). In the subsequent Synthesis Group report (Synthesis Group 1991), the concepts of aerobraking and vehicle reusability were abandoned for safety and cost considerations, in favor of an all propulsive, expendable mission mode. A dual launch Earth orbit rendezvous and dock (EOR\&D) scenario was adopted for vehicle assembly and a "direct capsule reentry" at Earth return eliminated the need for a LEO transportation node.

Concurrent with aerobraking and chemical propulsion concept studies, the benefits of a NTR-based LTS was examined at the NASA Lewis Research Center (Borowski 1991). With its factor of two advantage in Isp over chemical propulsion and its attractive engine thrust-to-weight ratio ( 3-10), NTR propulsion enabled a fully reusable, all propulsive LTS for less IMLEO than even the partially reusable, aerobraked chemical systems baselined in the 90 Day Study. Reusability, however, required a LEO propellant depot or expendable propellant tanker for $\mathrm{LH}_{2}$ refueling. The use of low density $\mathrm{LH}_{2}$ also increased the NTR LTV size and necessitated larger diameter payload shrouds (e.g., Shuttle C-Block II in Figure 1) to launch the necessary vehicle components.

Oxygen's abundance ( $\sim 45 \%$ by mass) in the lunar regolith (Sullivan and McKay 1991) represents a valuable resource which can be exploited for lunar base development. By providing LUNOX for power, life support and propulsion systems, dramatic reductions in IMLEO and lunar base operating costs are predicted. The LANTR 

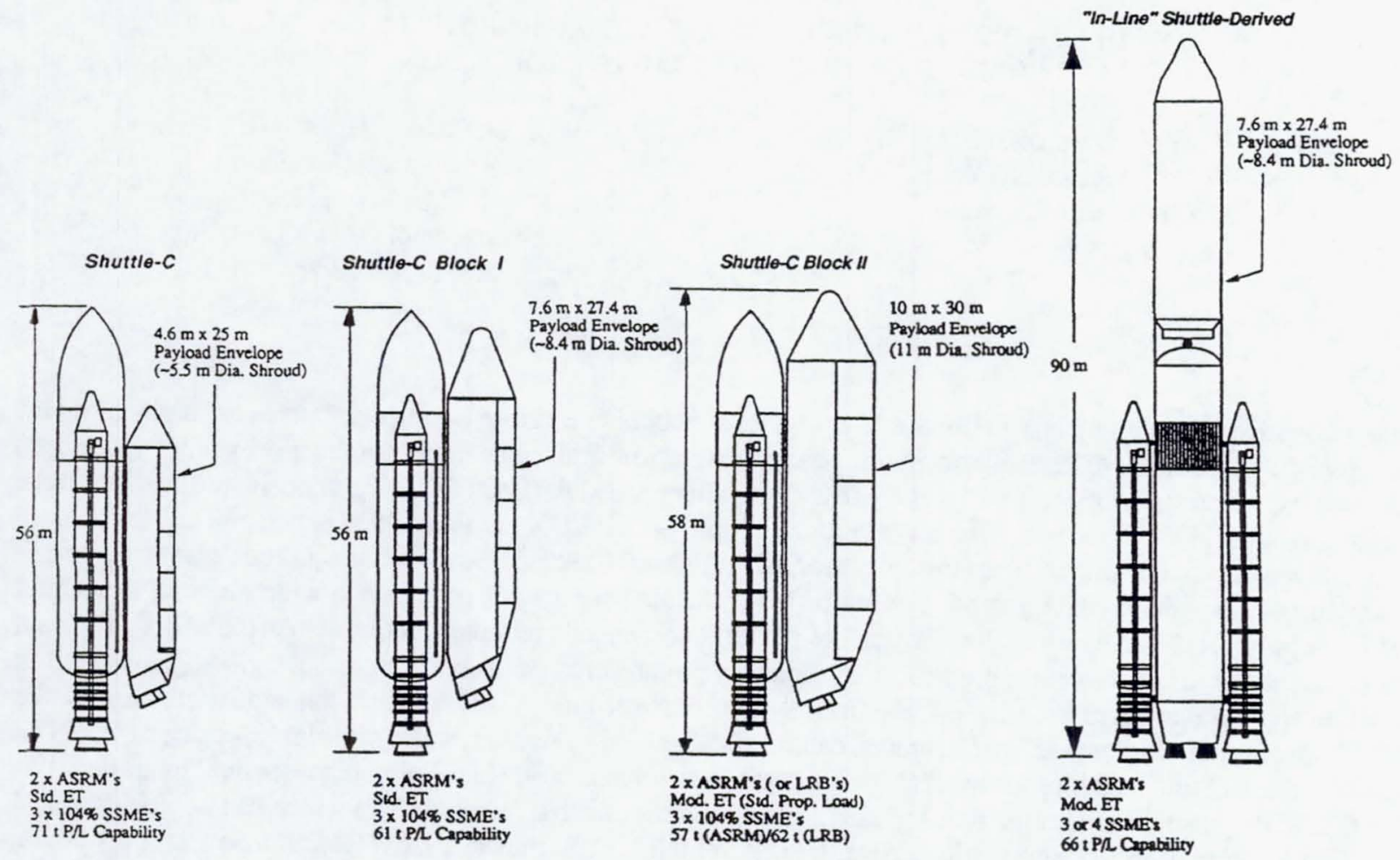

FIGURE 1. Shuttle-Based Options for Lunar Launch Vehicles.

concept described here leverages the high Isp capability of the NTR and the availability of LUNOX and provides the basis for a revolutionary LTS architecture (Borowski et al. 1994) possessing a variety of engine, vehicle and mission benefits. The implementation strategy for this architecture uses expendable "all $\mathrm{LH}_{2}$ " NTR systems initially to maximize the surface landed payload per mission while minimizing IMLEO requirements. This approach allows us to use near term Shuttle C or SDV technology which analysis (Rutledge 1994) indicates would be cheaper to develop and operate than the reusable, reduced-payload-capability, Single Stage to Orbit (SSTO) vehicle. The increased payload delivered on each expendable NTR flight is also leveraged to land surface systems dedicated to lunar resource utilization. Our intent here is to use LUNOX to "reoxidize" LLVs and LTVs at the earliest possible opportunity (ExPO 1992, Joosten and Guerra 1993) and to then transition to a reusable LTS architecture to minimize recurring costs to the point where commercialization and human settlement of the Moon can become practical.

\section{THE LOX-AUGMENTED NTR CONCEPT}

The trimodal LANTR engine, shown in Figure 2, operates in three different modes: thrust with hydrogen propellant, electric power only, and thrust with oxygen and hydrogen propellants. The LANTR contains a reactor and nozzle to heat and expand propellant, hydrogen and oxygen feed systems with autogenous gas bleed for tank pressurization, and a closed Brayton power cycle for engine cooldown, deep throttling, and electric power generation. The hydrogen feed system is powered by engine waste heat using a highly recuperated topping cycle which enables the engine to run at a nozzle inlet pressure of 2000 psia. This and the fact that the recuperator also doubles as the reactor's cooled gamma radiation shield reduces engine size and mass. The hydrogen system generates electricity by bleeding through the Brayton cycle turbine, which drives an electric motor/generator and a compressor. The latter is used during closed loop and low power operation for hydrogen gas circulation, reactor cooldown, and electric power generation. An "on-off" valve, located in the subsonic rocket nozzle, is shut during closed loop modes of operation to prevent leakage of hydrogen working fluid to space, and opened to the hot hydrogen exhaust during thrust mode operation. Waste heat is rejected to space using a combination of nozzle and heat pipe radiators (see Figure 2).

During bipropellant operation the oxygen feed system uses a topping cycle powered by an oxidizer-rich preburner. Downstream nozzle injection isolates the reactor core from oxygen damage provided the throat retains choked flow. 


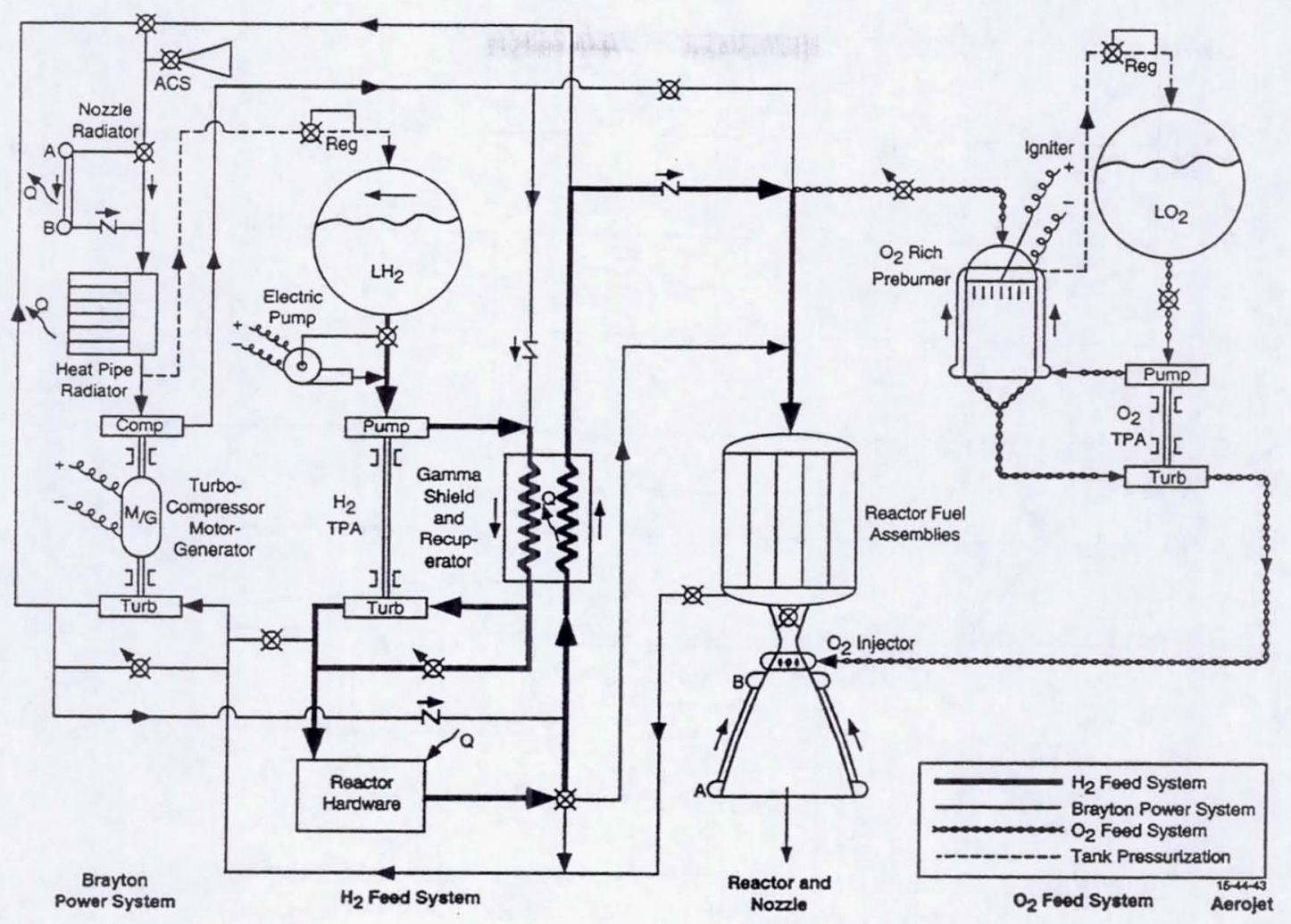

FIGURE 2. Flow Schematic of LOX-Augmented NTR Engine.

This condition is satisfied using a "cascade" scramjet injector concept developed by Aerojet which controls oxygen addition and heat release profiles (via staged injection) to keep the flow supersonic (Borowski et al. 1994). It also increases penetration, mixing and combustion of the oxygen injectant in the supersonic hydrogen flow while minimizing shock losses and high heat flux regions (hot spots), thereby maximizing engine performance and life. The high reactor outlet pressure of the LANTR $(\sim 2000 \mathrm{psia})$ also enables high area ratio nozzles $(\varepsilon=500$ to 1$)$, important for combustion efficiency, at reasonable size and mass.

An extremely versatile feature of the LANTR is its ability to operate over a wide range of thrust and Isp values by varying the engine's oxygen-to-hydrogen $(\mathrm{O} / \mathrm{H})$ mixture ratio $(M R)$. Figures 3 and 4 show the variation of engine thrust-to-weight $\left(\mathrm{T} / \mathrm{W}_{\mathrm{e}}\right)$ ratio, bipropellant tank fraction and Isp with $\mathrm{MR}$. As the MR varies from zero to seven, the $\mathrm{T} / \mathrm{W}_{\mathrm{e}}$ ratio for a $15 \mathrm{klbf}$ LANTR increases by $\sim 440 \%--\mathrm{from} \sim 3$ to 13 . This thrust augmentation feature means that small $\mathrm{LH}_{2}$-cooled NTR engines can be developed and tested on Earth in affordable "contained" facilities and then operated in space in the augmented high thrust mode to reduce Earth escape gravity losses and eliminate the need for perigee propulsion. The bipropellant tank fraction also decreases with increasing $M R$, dropping by $\sim 540 \%$--from $14 \%$ to $\sim 2.6 \%$ at $M R=7$, while the Isp degrades by only $\sim 45 \%$-from 940 to 515 seconds. The LANTR concept provides the space vehicle designer substantial flexibility to accommodate a wide variety of mission needs, as well as, volume- and/or mass-constrained launch vehicle designs.

\section{LUNAR MISSION SCENARIOS/VEHICLE DESCRIPTIONS}

The reference lunar architecture includes both cargo and piloted lander missions conducted initially in an expendable mode. Key ground rules and assumptions associated with the mission scenario and transportation system are summarized in Tables 1 and 2, respectively. The LTS elements for each mission are launched into LEO using two "in-line" SDVs, each with a lift capability of $\sim 66 \mathrm{t}$. Figure 5 illustrates the chemical propulsion version of the piloted mission which assumes a capsule reentry at mission end. The first SDV flight launches the $\mathrm{LOX} / \mathrm{LH}_{2}$-fueled trans-lunar injection (TLI) stage. The second SDV flight launches the lunar orbit insertion/trans-Earth injection 


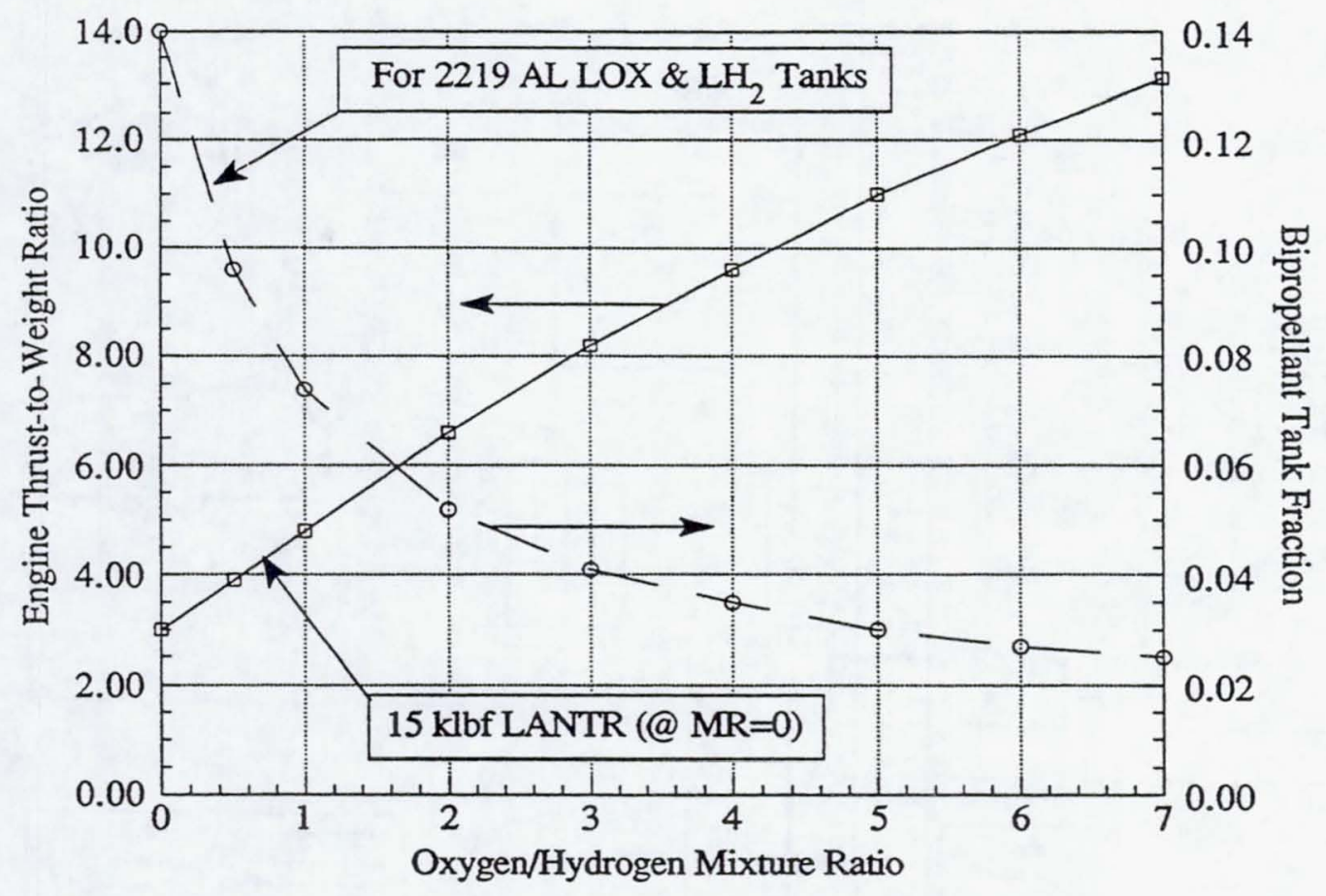

FIGURE 3. Variation of Engine Thrust-to-Weight Ratio \& Bipropellant Tank Fraction With $\mathrm{O} / \mathrm{H}$ Mixture Ratio.

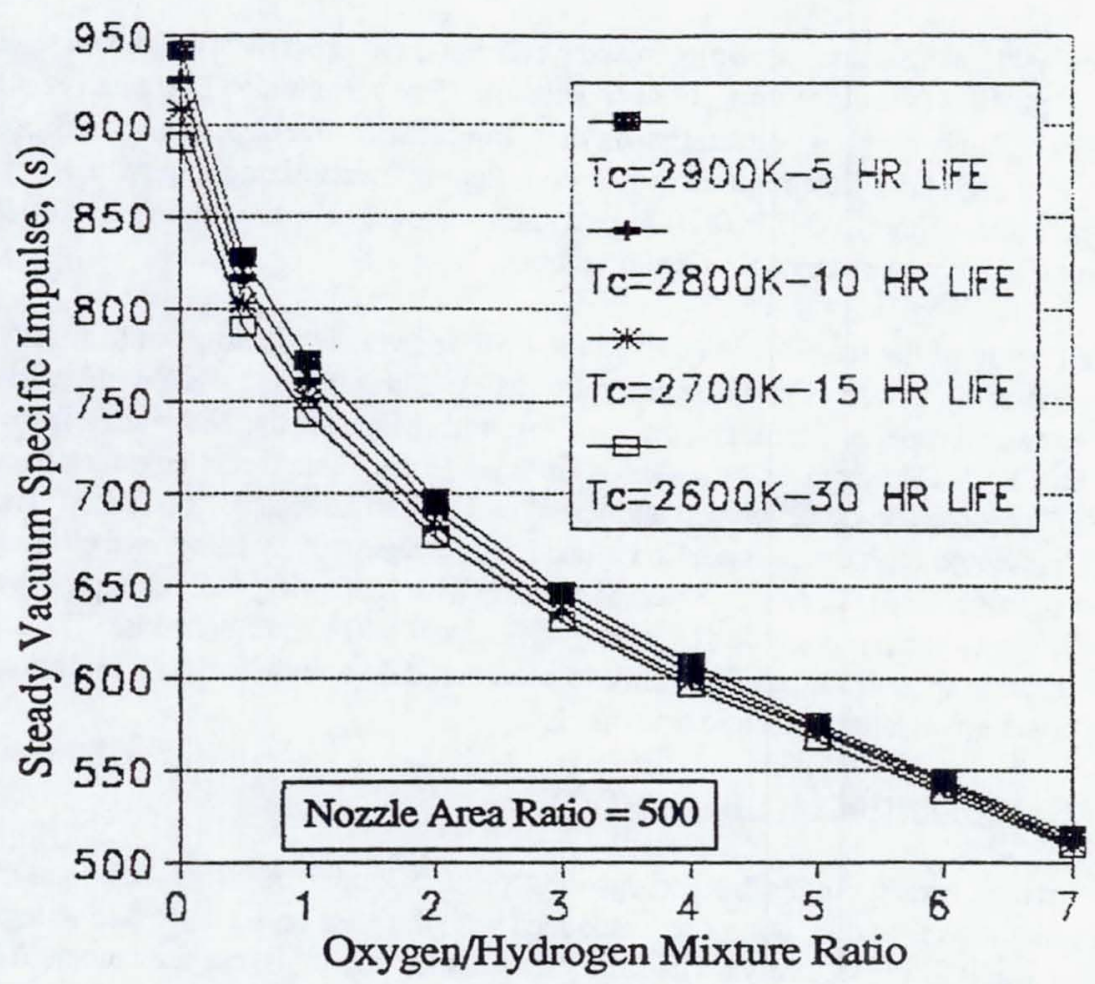

FIGURE 4. Variation of Specific Impulse With O/H Mixture Ratio. 
TABLE 1. Reference Lunar Mission Ground Rules and Assumptions.

- Payload Outbound:

$9.9 \mathrm{t} \quad$ LTV crew module

$0.8 \mathrm{t}$ Crew (4) and suits

5.0-10.0 t Lunar surface payload

$5.0 \mathrm{t} \quad \mathrm{WV}$ crew module

35.7-46.0 t "Wet" LLV stage

- Payload Inbound:

9.9 t LTV crew module

$0.8 \mathrm{t}$ Crew (4) and suits

$0.5 \mathrm{t} \quad$ Lunar samples

- Parking Orbits:

$407 \mathrm{~km} \quad$ Circular (Earth departure)

$300 \mathrm{~km}$ Circular (lunar arrival/departure)

- Trans-lunar injection $\Delta \mathrm{V}$ assumed to be $3100 \mathrm{~m} / \mathrm{s}+\mathrm{g}$-losses

- Lunar orbit capture/trans-Earth injection $\Delta V$ 's assumed to be $915 \mathrm{~m} / \mathrm{s}$

- Earth return: Direct capsule entry

- Earth gravity assist disposal $\Delta V$ assumed to be $194 \mathrm{~m} / \mathrm{s}$ (for NTR system)

- Mission duration: 54 days* (2 in LEO, 7 in transit, 45 days at Moon)

- HLLV type/payload capability: "in-line" SDV/66 t to $407 \mathrm{~km}$ circular

- LTV assembly scenario: 2 HLLV launches with EOR\&D (IMLEO < 132 t)

" Chemical TLI and NTR "core" stages in LEO for 30 days prior to second HLLV launch

TABLE 2. Lunar NTR Transportation System Assumptions.

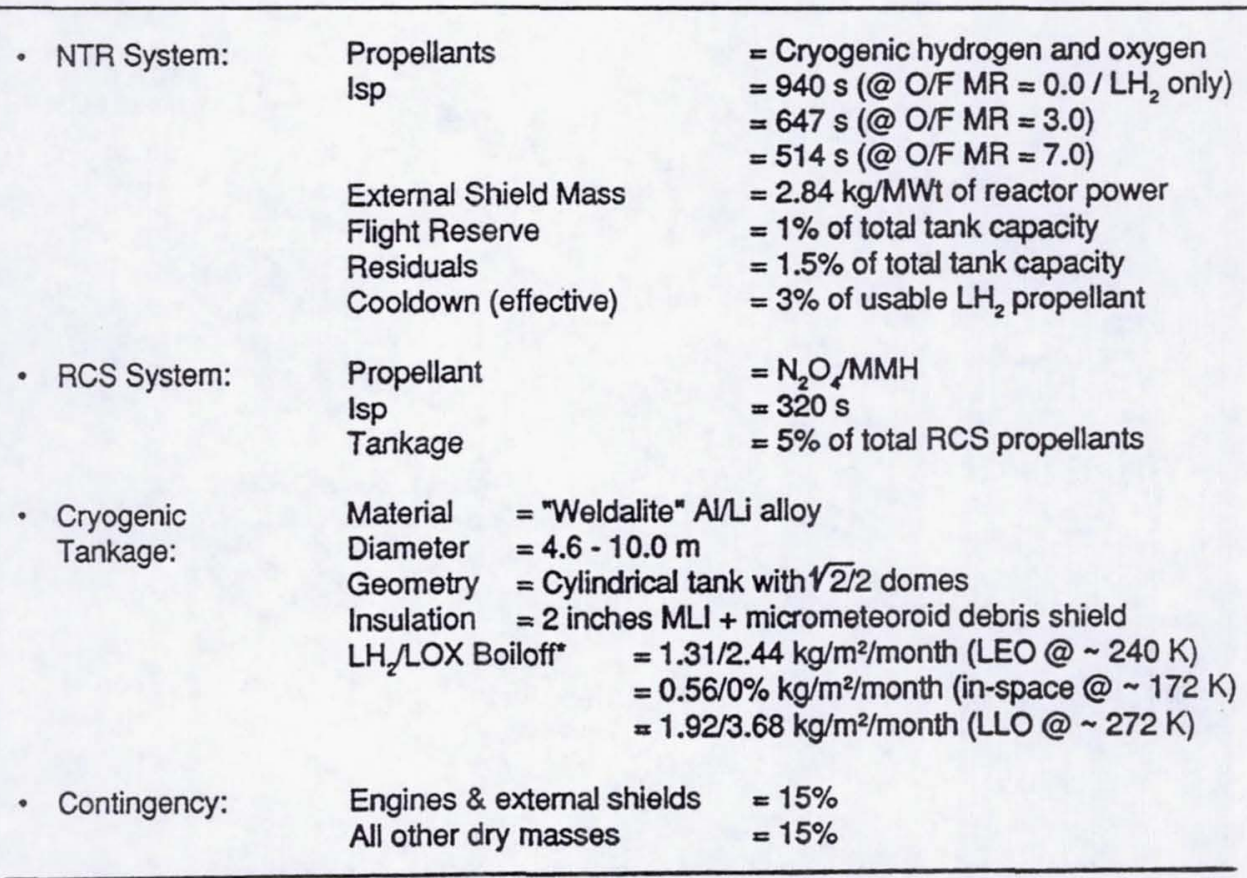

* Assumes $3 \times$ "Lockheed Eqn" heat flux estimates for MLI $\Delta t \sim 2$ inches 
(LOI/TEI) stage, the piloted crew module and the LLV and its surface payload. The LTS elements are then assembled into an integrated vehicle via an EOR\&D maneuver (see Figures 5 and 6a). After 2 days in LEO for system checkout, the TLI stage uses its 5 RL10-derivative engines (with Isp $-465 \mathrm{~s}$ ) to inject the piloted LOI/TEI stage and lander elements to the Moon and is then jettisoned. Three RL10 engines are used in the LOI/TEI stage to capture into and depart form lunar orbit after a 45 Earth day landing mission (covering a lunar day, night, day cycle). The LLV uses 5 throttleable RL10s and delivers $5 t$ of surface payload on the piloted missions. On cargo missions, the $5 \mathrm{t}$ crew cab is removed and $28 \mathrm{t}$ payloads can be delivered on "one way" trips to the lunar surface.

\section{Expendable NTR System Performance}

The relative size and mass of the chemical and NTR-powered piloted LTVs examined in this study are shown in Figure 6. The expendable "all $\mathrm{LH}_{2}$ " NTR vehicle is a " 2 tank" configuration (Figure $6 \mathrm{~b}$ ) also launched using two SDVs. The first SDV flight delivers the "core" stage which is powered by two $15 \mathrm{klbf}$ bimodal NTRs each capable of generating $\sim 15 \mathrm{kWe}$ of electrical power using a hydrogen working fluid, closed Brayton cycle power conversion unit (CBC/PCU). The bimodal design considered here was developed by a joint US/CIS (Commonwealth of Independent States) team under NASA funding (Culver et al. 1994). The CBC/PCU is enclosed within the conical extension of the stage thrust structure which also provides support for a $24 \mathrm{~m}^{2}$ heat pipe radiator required for the two engine system. Additional radiator surface area $\left(\sim 13 \mathrm{~m}^{2}\right)$ is provided by the bimodal NTR's large expansion ratio nozzles. Other "core" stage elements include: (1) two external radiation shields for crew protection; (2) a $7.6 \mathrm{~m}$ diameter by $17.5 \mathrm{~m}$ long $\mathrm{LH}_{2}$ tank; (3) a forward cylindrical adaptor housing the RCS system, avionics and auxiliary power, and docking system; and (4) forward and aft cylindrical band skirts. The mass of the "dry" core stage, and its RCS and $\mathrm{LH}_{2}$ propellant loads are $16.0,0.4$, and $49.3 \mathrm{t}$, respectively, for a total mass at liftoff of $-65.7 \mathrm{t}$. The "core" stage total length is a little over $24 \mathrm{~m}$, well within the $27.4 \mathrm{~m}$ payload length limit of the SDV/Shuttle CBlock I launch vehicles (see Figure 1).

The second SDV launch, 30 days later, delivers another $65.7 \mathrm{t}$ to LEO consisting of a second, smaller $\mathrm{LH}_{2}$ tank with its "conical" core stage adaptor, the piloted LTV crew module and crew, and the LLV and its payload. The "inline" $\mathrm{LH}_{2}$ tank is $4.6 \mathrm{~m}$ in diameter and $9.0 \mathrm{~m}$ long and has a $9 \mathrm{t} \mathrm{LH}_{2}$ propellant capacity. After rendezvous and docking, the $46 \mathrm{~m}$ long NTR LTV and its payload depart for the Moon. A "single burn" Earth departure scenario is

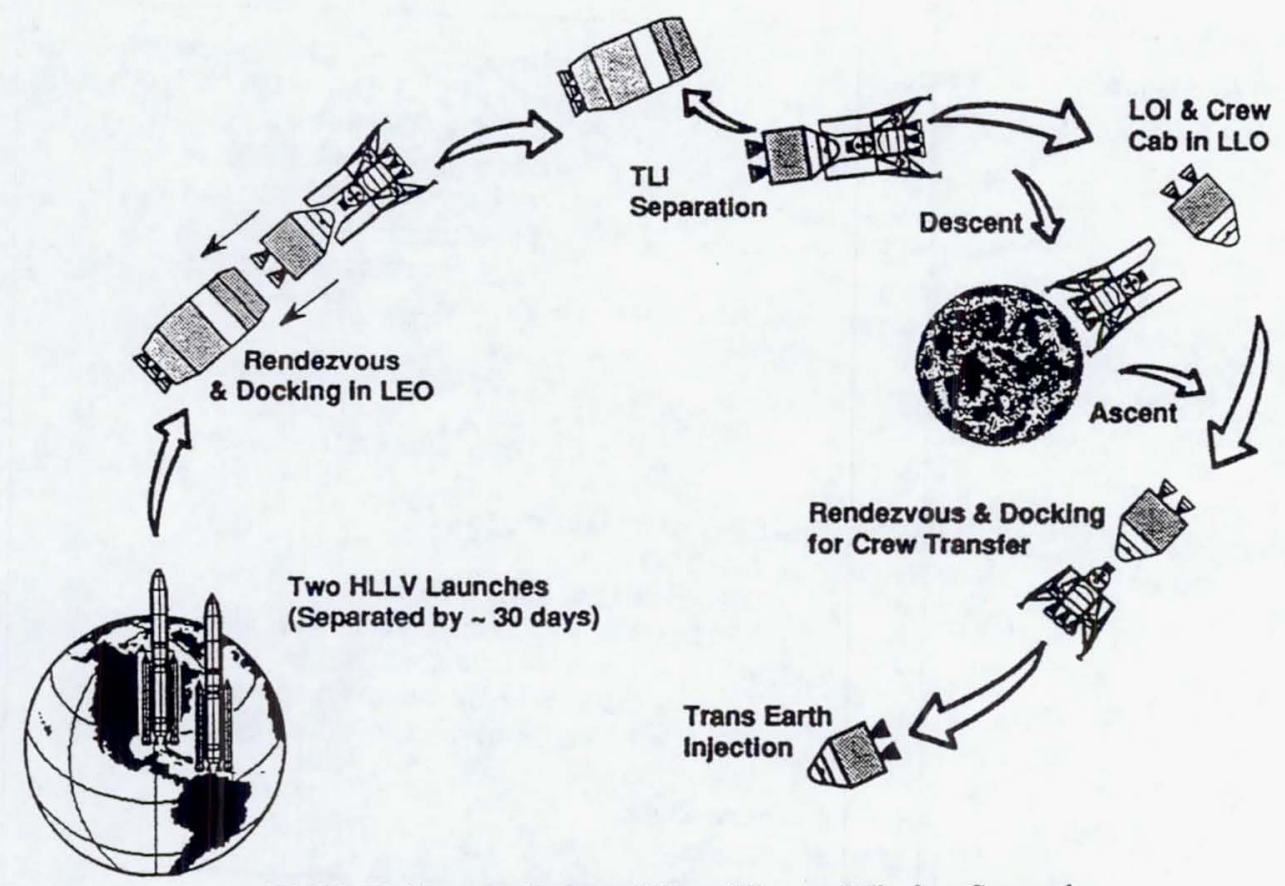

FIGURE 5. Reference Piloted Lunar Mission Scenario Using Two SDV Launches. 


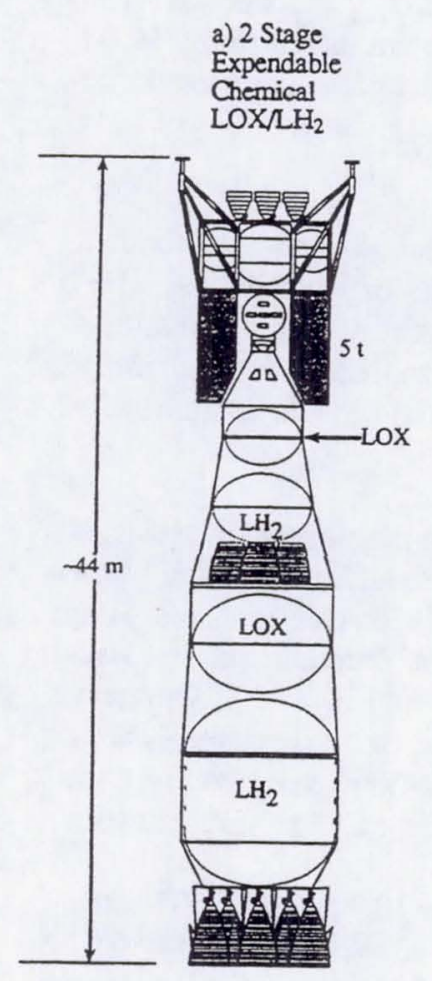

$\operatorname{IMLEO}(\mathrm{t})=132$ b) 2 Tank

Expendable NTR

$\mathrm{LH}_{2}$ Only
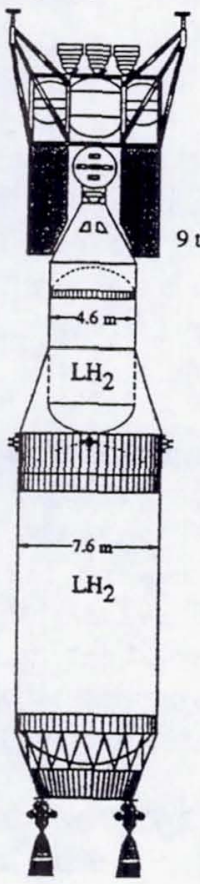

132

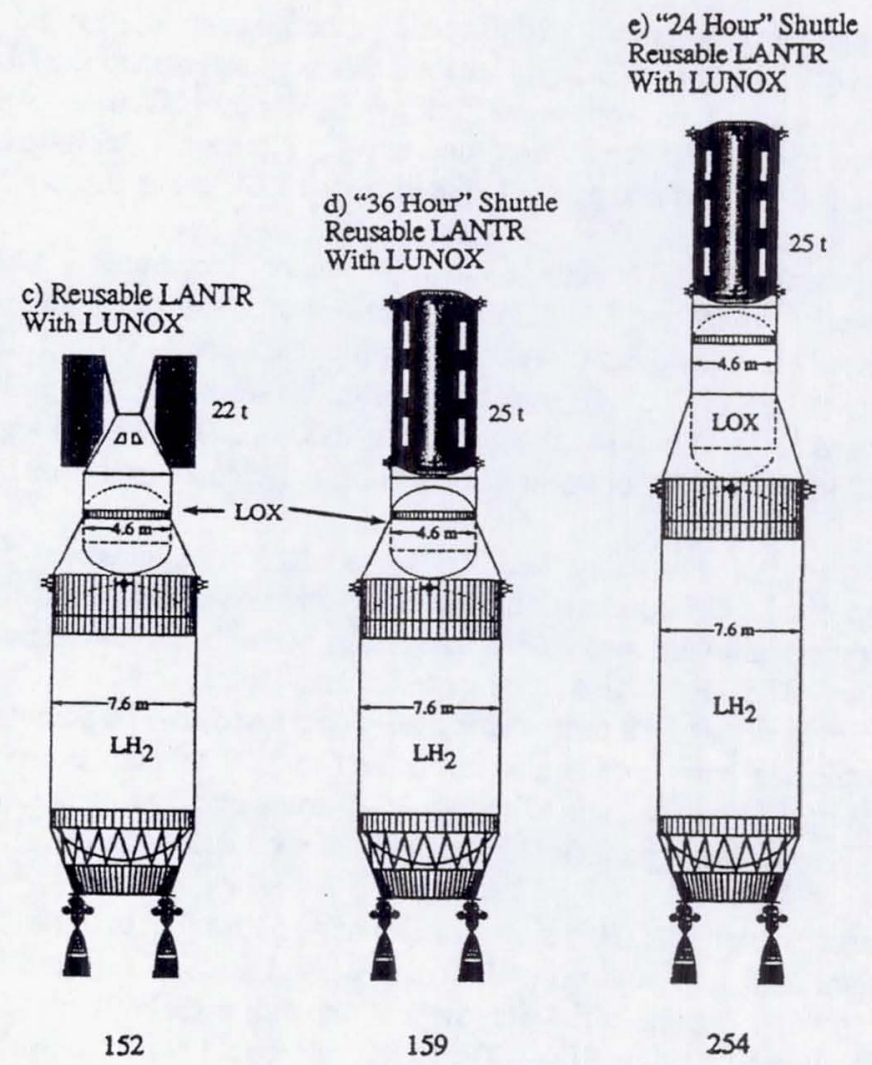

e) "24 Hour" Shuttle

With LUNOX

254

FIGURE 6. Relative Size/Mass of Chemical \& NTR Vehicles With \& Without LOX Augmentation.

assumed and includes gravity losses of $\sim 392 \mathrm{~m} / \mathrm{s}$. The TLI burn duration is $\sim 47.5$ minutes and the total mission burn time for the two $15 \mathrm{klbf}$ NTRs is $\sim 61.4$ minutes.

Because of its high Isp ( $940 \mathrm{~s})$, the NTR-powered piloted LTV can transport a larger LLV to LLO capable of landing $9 \mathrm{t}$ of surface payload--an $80 \%$ increase over the chemical LTV system for the same IMLEO. On cargo missions, payloads on the order of $34 \mathrm{t}$ can be delivered to the lunar surface by the chemical LLV representing a $378 \%$ increase over the piloted mission mode. The NTR system also appears to be less complex with fewer stages and engines. After LOR and docking of the piloted LLV with the NTR LTV, and transfer of crew and lunar samples to the LTV crew module, the LLV is jettisoned and the core stage performs a TEI burn to return to Earth. Following separation of the LTV crew cab for its ballistic reentry to Earth, the NTR LTV performs a final small $(\sim 194 \mathrm{~m} / \mathrm{s})$ Earth perigee burn resulting in "long-term disposal" of the stage into heliocentric space. This same disposal scenario is also repeated on cargo missions.

\section{LANTR System Performance with LUNOX}

Once LUNOX becomes available in LLO for "reoxidizing" the LANTR LTV, monopropellant NTRs would be outfitted with an oxygen propellant module, feed system and afterbumer nozzle for bipropellant operation. The lunar mission scenario now transitions from an expendable to a "reusable" mode with the piloted LANTR system capable of delivering $\sim 27 \mathrm{t}$ of cargo and Earth-supplied $\mathrm{LH}_{2}$ into $\mathrm{LLO}$. Crew and cargo are transported to the lunar surface by reusable LLVs that are now maintained and refueled at the lunar outpost. In the reusable mode, however, the LLV has a reduced cargo delivery capability because the lander's tankage and propellant load $\left(-22.3 \mathrm{t}\right.$ of ${\mathrm{LOXN} / \mathrm{LH}_{2}}$ at $M R=6$ ) was sized to deliver $\sim 9$ t of surface payload on the initial expendable piloted missions. When the LLV (which has a "dry" mass of $11.4 \mathrm{t}$ including its $5 \mathrm{t}$ crew cab) operates from the lunar outpost, $\sim 11.5 \mathrm{t}$ of propellant is used in ascending to LLO for rendezvous with the LTV. This estimate assumes an ascent $\Delta V$ of $\sim 1900 \mathrm{~m} / \mathrm{s}$ and an Isp of $\sim 465 \mathrm{~s}$ for the LLV. To land $27 \mathrm{t}$ of cargo and $4 \mathrm{crew}$ on the lunar surface requires $\sim 21.7 \mathrm{t}$ of propellant 
assuming a descent $\Delta \mathrm{V}$ of $\sim 2000 \mathrm{~m} / \mathrm{s}$. In the mission strategy adopted here, the LANTR LTV is loaded with an additional $10.9 \mathrm{t}$ of $\mathrm{LOX} / \mathrm{LH}_{2}$ propellant that is transferred to the $\mathrm{LLV}$ after LOR to supplement its remaining $10.8 \mathrm{t}$ propellant load. This "topping off" of the LLV's propellant tanks allows the crew and entire cargo shipment to be delivered to the surface on one round trip LLV mission. Included in the $27 \mathrm{t}$ of surface payload is $\sim 6.0 \mathrm{t}^{-} \mathrm{LH}_{2}$ propellant $(\sim 5 \mathrm{t})$ and tankage $(\sim 1 \mathrm{t})$ used by the LLV on its subsequent mission.

The reusable LANTR vehicle shown in Figure $6 c$ operates at a MR $=3$ (Isp $\sim 647 \mathrm{~s}$ ) both outbound and inbound, refuels with $\sim 21.2 \mathrm{t}$ of LUNOX for Earth return, and is a smaller overall vehicle than its expendable "all $\mathrm{LH}_{2}$ " counterpart, even with its increased performance. The LOX tank diameter and overall length are both $4.6 \mathrm{~m}$ and its capacity is $\sim 65 \mathrm{t}$. The $\mathrm{LH}_{2}$ tank is $7.6 \mathrm{~m}$ in diameter and $15 \mathrm{~m}$ in length but is only filled to $\sim 85 \%$ of its maximum $\mathrm{LH}_{2}$ capacity $(-41.5 \mathrm{t})$ for this particular mission. The $15 \mathrm{~m}$ long tank is baselined here to provide commonality with a "36 hour" rapid cislunar nuclear shuttle discussed in the next section.

Compared to monopropellant NTRs, the LANTR engines are 5\% longer (an expansion ratio of 500 to 1 is used for improved LOX combustion efficiency) and $\sim 6 \%$ heavier (attributed to the larger nozzle and the addition of the LOX propellant feed system). However, at $M R=3$, the thrust output (F) from two $15 \mathrm{klbf}$ LANTRs increases by $275 \%$ to $-82.5 \mathrm{klbf}$. This augmented thrust level significantly reduces the TLI burn duration and g-losses to 17.2 minutes and $72 \mathrm{~m} / \mathrm{s}$, respectively, compared to 47.5 minutes and $392 \mathrm{~m} / \mathrm{s}$ for the "all $\mathrm{LH}_{2}$ " $30 \mathrm{klbf}$ system. Total mission burn time is also cut in half to 28.9 minutes compared to 61.4 minutes for the expendable system. Because the LANTR engine lifetime is $\sim 5$ hours at a hydrogen exhaust temperature of $\sim 2900 \mathrm{~K}$ (see Figure 4), the LANTR system can perform 10 round trip lunar missions before replacement thereby reducing LTS recurring costs.

The reusable LANTR has an IMLEO of $\sim 151.8 \mathrm{t}$ that includes the $17.5 \mathrm{t}$ "dry" stage, a $10.7 \mathrm{t}$ piloted LTV crew module, $22.0 \mathrm{t}$ of non-propellant cargo, and $\mathrm{RCS}, \mathrm{LH}_{2}$, and LOX propellant loads of $\sim 2.7,34.5$ and $65 \mathrm{t}$, respectively. During initial deployment, the entire LANTR LTV, including its RCS and $\mathrm{LH}_{2}$ propellant loads, can be launched on a single SDV. The LOX tank would require on-orbit filling from an expendable propellant tanker or propellant depot. For subsequent piloted missions, the total mass needed to outfit and refuel the LTV stage is $\sim 123.2 \mathrm{t}$ and can again be launched on two $66 \mathrm{t}$-class SDVs.

Approximately $40.3 \mathrm{t}$ of LUNOX ( $21.2 \mathrm{t}$ for LTV return and $19.1 \mathrm{t}$ for the LLV) must be produced to support each reusable mission. Automated, modular LUNOX production units and teleoperated mining equipment would be delivered to LLO by monopropellant and later LANTR systems, and then transported to the surface using on-board chemical propulsion. A 24 metric ton per year (t/year) LUNOX production unit based on hydrogen reduction of ilmenite $\left(\mathrm{FeTiO}_{3}\right)$ would have a total mass of $\sim 17.3 \mathrm{t}$ (Christiansen 1988), composed of an $80 \mathrm{kWe}$ nuclear power system for continuous lunar day/night operation, equipment for mining, ilmenite beneficiation and processing. A single SDV could launch the entire production unit including its power system and lunar landing stage. Total plant mass and power requirements will vary of course with the LUNOX production rate increasing to $63.7 \mathrm{t}$ and $485 \mathrm{kWe}$, respectively, for 6 modular units having a 144 t/year capacity (Christiansen 1988).

\section{Rapid Cislunar Nuclear Shuttle}

With LUNOX production underway and a reusable, LANTR LTV in service, the lunar outpost will expand to a permanent settlement staffed by visiting scientists and engineers representing both government and private commercial ventures. Convenient cislunar transportation, comparable to today's 24 hour flights from Washington, D.C. to Sydney, Australia, will make the Moon accessible to greater numbers of people and increase prospects for its commercial development. With the LANTR concept, one way flight times to and from the Moon of 36 to 24 hours appear possible with reasonable size vehicles and IMLEO values.

The $\Delta \mathrm{V}$ requirements for TLI and LOI as a function of "one way" flight time are shown in Figure 7. For transit times less than 48 hours, the TLI and particularly the LOI $\Delta V$ requirements increase dramatically. The "free return" to Earth option of the Apollo program is no longer available, and the outbound trajectory is that of a hyperbolic Earth departure necessitating multiple spacecraft engines for passenger safety. The "ideal" TLI and LOI total $\Delta \mathrm{V}$ requirement, for 24 and 36 hour transit times, are 6.9 and $5.1 \mathrm{~km} / \mathrm{s}$, respectively, compared to $-4.1 \mathrm{~km} / \mathrm{s}$ for the 3.5 day reference lunar mission. 


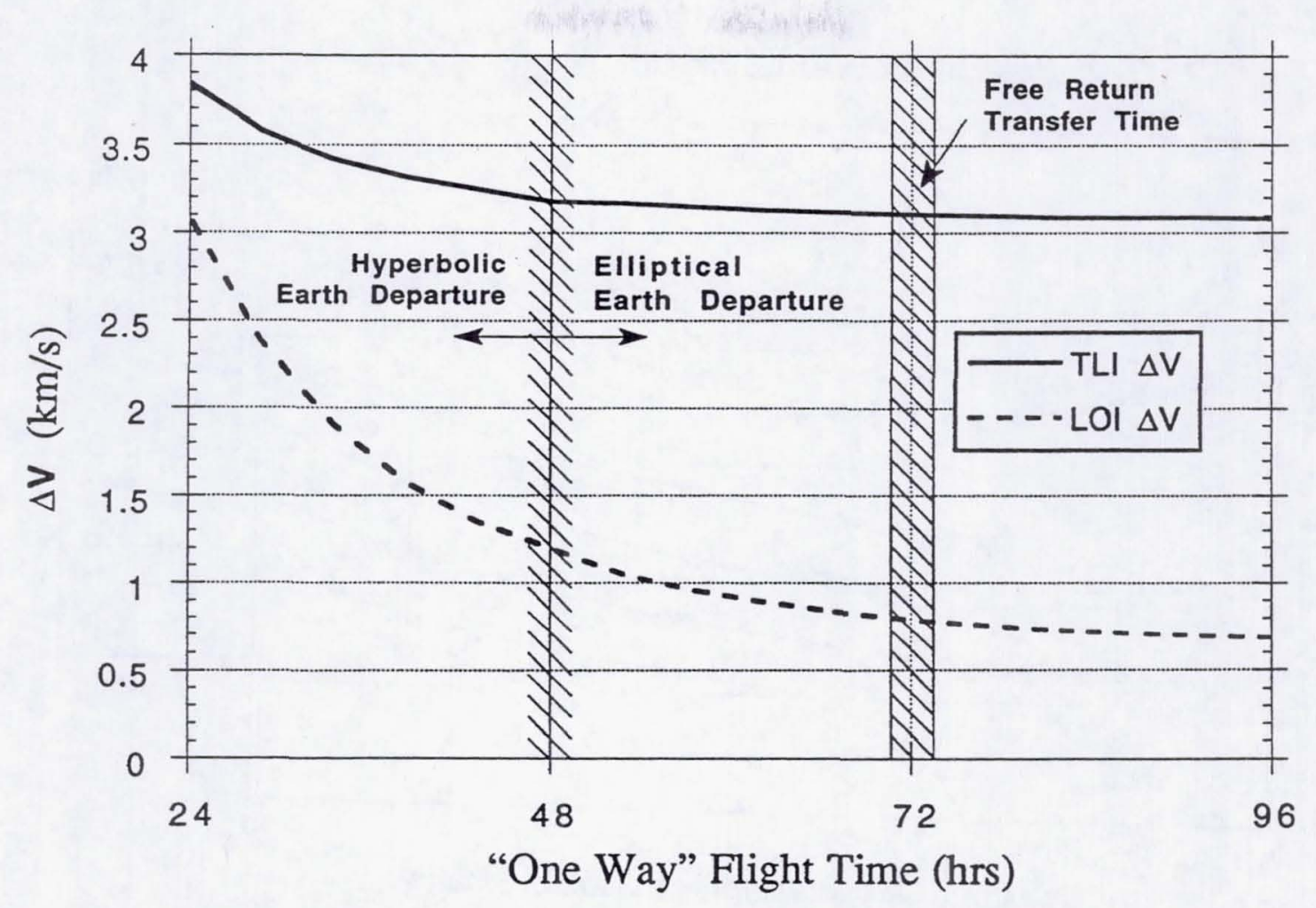

FIGURE 7. TLI and LOI $\triangle V$ Variation With "One Way" Flight Time (300 km Lunar Orbit).

A "36 hour" LANTR shuttle capable of transporting a $25 \mathrm{t}$ passenger module to and from the Moon is shown in Figure 6d. It has an IMLEO of $\sim 159 \mathrm{t}$, and is powered by two LANTR engines which produce $82.5 \mathrm{klbf}$ of thrust using an outbound and inbound $M R=3$. The spacecraft's LOX tank is $4.6 \mathrm{~m}$ in diameter and $4.9 \mathrm{~m}$ long and holds $70.5 \mathrm{t}$ of Earth-supplied LOX required for the outbound trip. It is resupplied in LLO with $48.5 \mathrm{t}$ of LUNOX for the 36 hour return trip to Earth. The $\mathrm{LH}_{2}$ tank is $7.6 \mathrm{~m}$ in diameter and $15 \mathrm{~m}$ long and carries $\sim 41.5 \mathrm{t}$ of $\mathrm{LH}_{2}$ required for the round trip mission. The mass breakdown of the LANTR shuttle includes the $20.5 \mathrm{t}$ "dry" stage, a $25 \mathrm{t}$ passenger module, and RCS, $\mathrm{LH}_{2}$ and LOX propellant loads of $1.6,41.4$, and $70.4 \mathrm{t}$, respectively. Resupplying these propellant requirements for subsequent missions can again be easily accommodated within the $132 \mathrm{t}$ lift capability of two $66 \mathrm{t}$-class SDVs. The total engine burn time for this mission is also attractive at $\sim 45$ minutes. Parametric data showing IMLEO variation with different outbound and inbound MR combinations for 36 and 24 hour "one way" trip times is shown in Figures 8 and 9, respectively.

Decreasing transit times from 36 to 24 hours increases $\Delta V$ and IMLEO requirements significantly by $\sim 35 \%$ and $60 \%$, respectively. A representative " 24 hour" LANTR vehicle is shown in Figure 6e. Its two engines operate at an outbound $M R=4(F \sim 96.9 \mathrm{klbf}$ and Isp $\sim 607 \mathrm{~s}$ ) and an inbound $M R=6(\mathrm{~F} \sim 121.8 \mathrm{klbf}$ and Isp $\sim 545 \mathrm{~s})$. The shuttle's LOX tank is $4.6 \mathrm{~m}$ in diameter and $\sim 9 \mathrm{~m}$ long and holds $\sim 146 \mathrm{t}$ of Earth-supplied LOX for the outbound lunar flight. It is resupplied in LLO with $\sim 120 \mathrm{t}$ of LUNOX for the 24 hour return trip to Earth. The $\mathrm{LH}_{2}$ tank is $7.6 \mathrm{~m}$ in diameter and $\sim 20.6 \mathrm{~m}$ in length ( $3.1 \mathrm{~m}$ longer than the expendable NTR system"s "core" tank) and carries $\sim 59 \mathrm{t}$ of $\mathrm{LH}_{2}$ required for the round trip mission. The " 24 hour" shuttle has an IMLEO of $\sim 253.7 \mathrm{t}$ that includes the $22.2 \mathrm{t}$ "dry" vehicle, the $25 \mathrm{t}$ passenger module, and $\mathrm{RCS}, \mathrm{LH}_{2}$ and $\mathrm{LOX}$ propellant loads of $2.0,59.0$ and $145.5 \mathrm{t}$, respectively. Total engine burn time for the " 24 hour" mission is just under 64 minutes with the longest single burn being the TLI maneuver at $\sim 29$ minutes. The $27.4 \mathrm{~m}$ payload length limit of the Shuttle-derived launch vehicles assumed in this study determines the maximum allowable "core" stage $\mathrm{LH}_{2}$ tank length and the corresponding outbound MR used here. While two SDV flights would be sufficient for deploying vehicle components, the initial and resupply propellant needs of the " 24 hour" LANTR shuttle exceed their combined $132 \mathrm{t}$ lift capability necessitating additional SDV launches. Excessive Earth-to-orbit launch costs could make shipment of LUNOX to LEO a commercial viable product for future high energy lunar missions. 


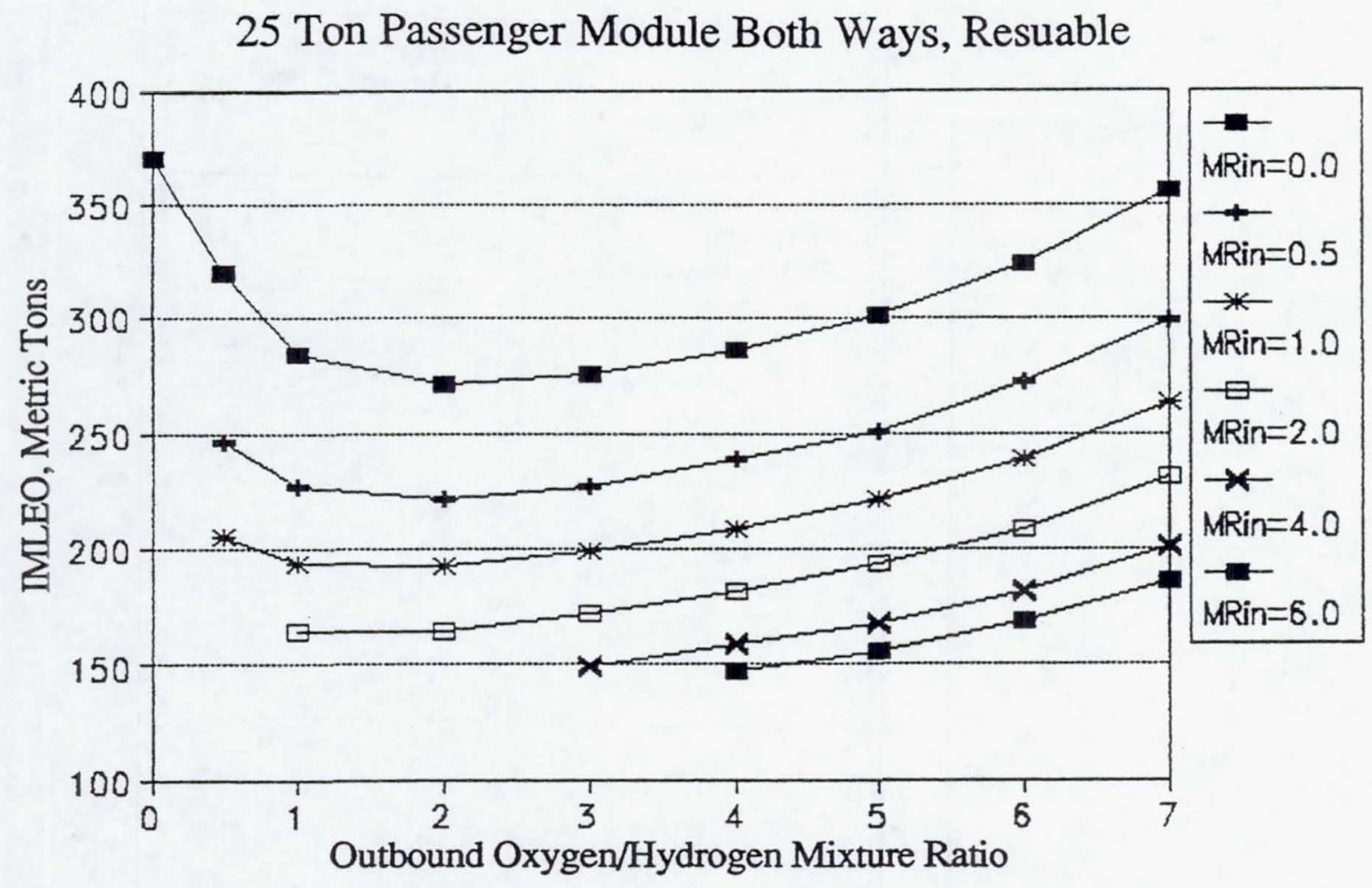

FIGURE 8. Variation of IMLEO With O/H Mixture Ratio for "36 Hour" Lunar Transfer.

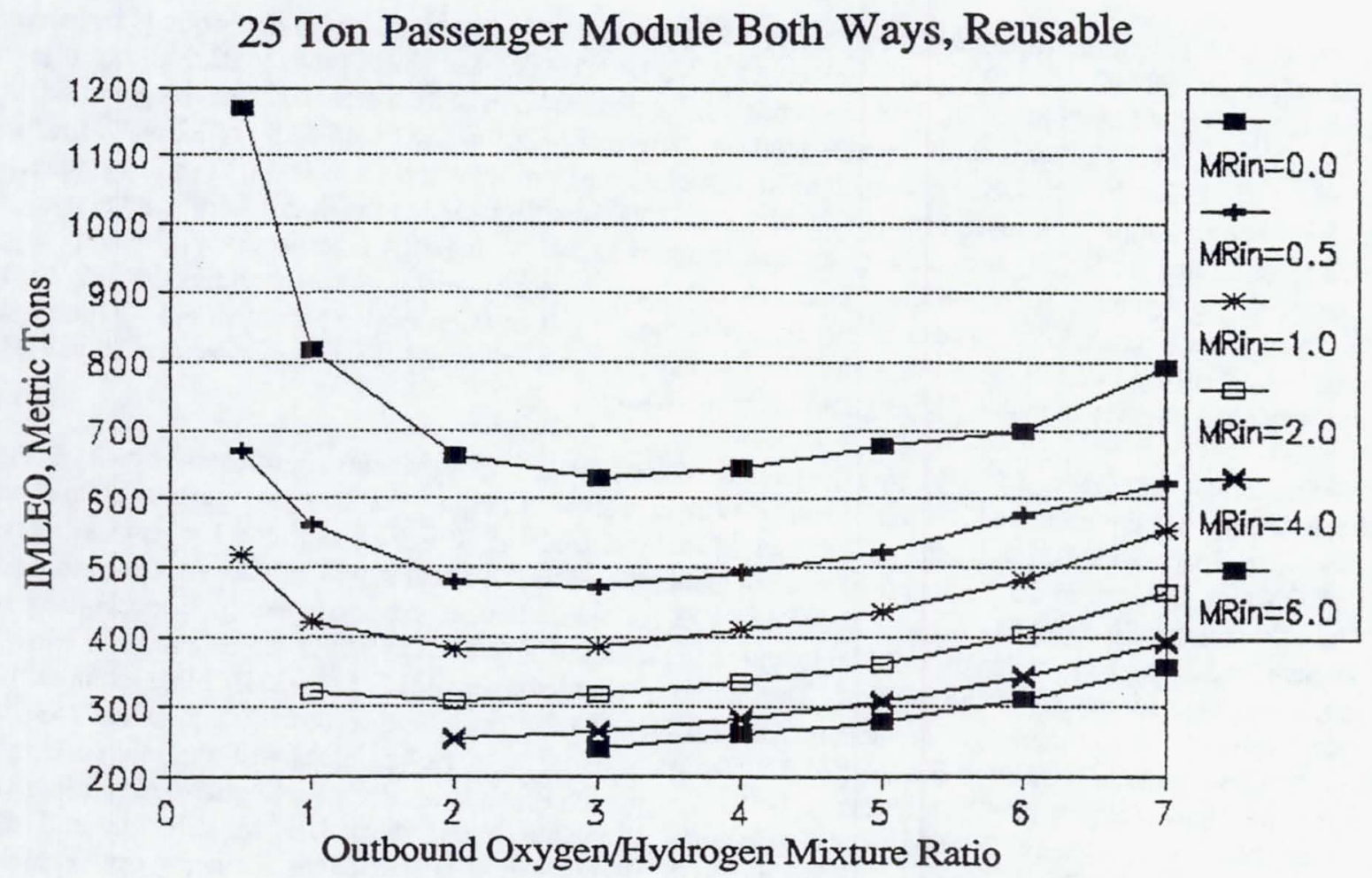

FIGURE 9. Variation of IMLEO With O/H Mixture Ratio for " 24 Hour" Lunar Transfer. 
A possible scenario for a quick "commuter" trip to the Moon would start with airbreathing/scramjet SSTO transport of passengers to an international space station (ISS). There they would enter a short duration "passenger" module containing its own life support, I\&C and auxiliary propulsion systems. The passenger module then departs the ISS and docks with a fully fueled LANTR shuttle awaiting it a safe distance away from the ISS. After a 24 to 36 hour transit to LLO, the passenger module detaches and docks with a waiting LLV (shown in Figure 10) for transport to the lunar surface. There it would be lowered to a "flat-bed" surface vehicle (see Figure 11) and transported to the lunar base air lock for docking and passenger unloading. Besides high energy lunar missions, the LANTR can also dramatically improve space transportation system performance wherever extraterrestrial sources of LOX and $\mathrm{LH}_{2}$ can be acquired such as the Martian system, main-belt asteroids and the Galilean satellites Europa, Ganymede, and Callisto (Borowski et al. 1994).

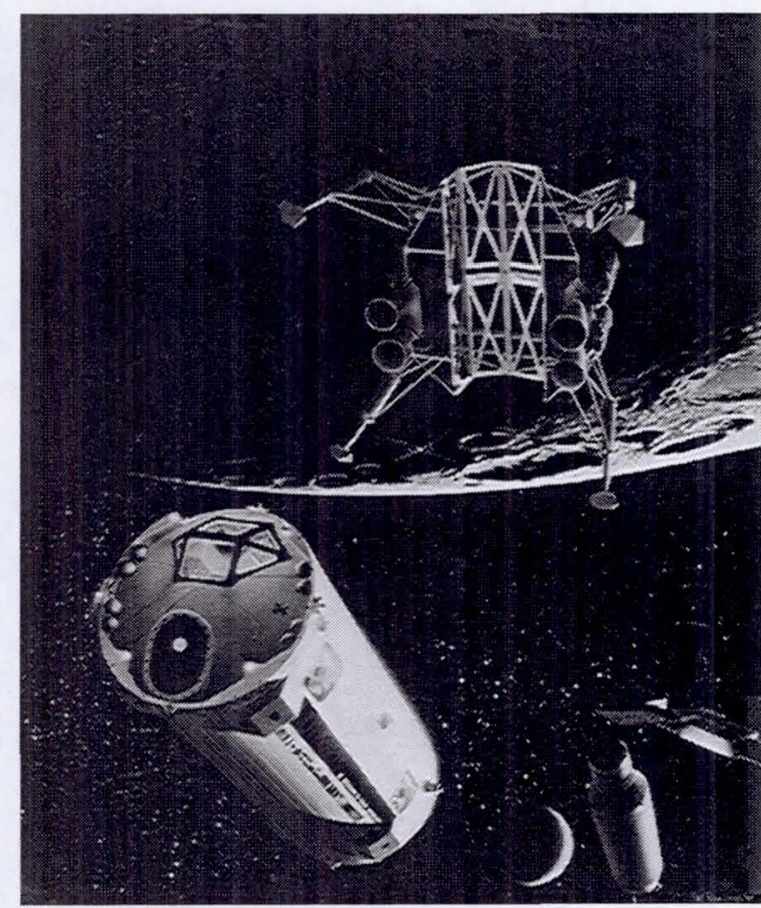

FIGURE 10. Artist's Illustration of "Commuter" Passenger Module Transferring From LANTR Stage to LLV in LLO.

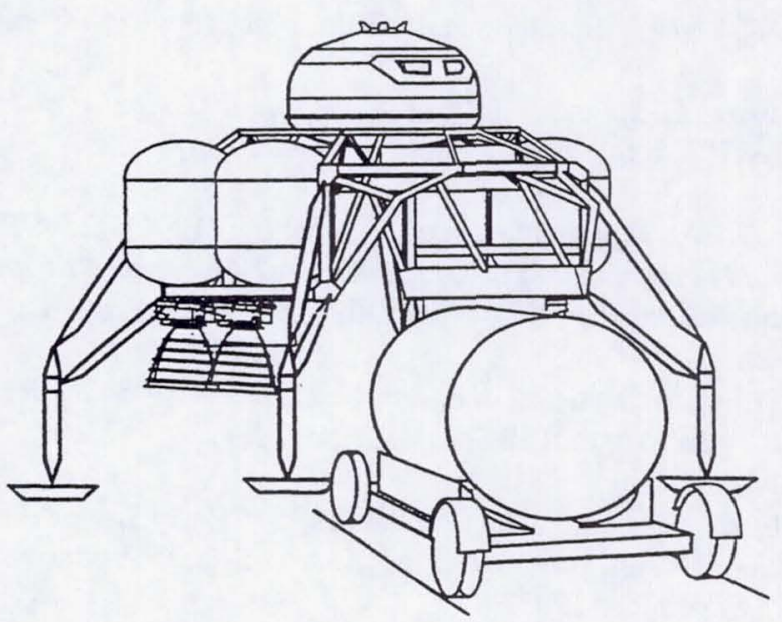

FIGURE 11. Surface Transport of Passenger Module to Lunar Base.

\section{SUMMARY AND CONCLUSIONS}

This paper describes operational characteristics and performance benefits of a versatile new engine concept--the LOX-augmented NTR. Combining conventional $\mathrm{LH}_{2}$-cooled NTR and scramjet propulsion technologies in the form of a LOX "afterburner nozzle" and propellant feed system, the LANTR can operate at O/H mixture ratios up to $\mathrm{MR}=7$ resulting in a variable thrust and Isp capability. In the augmented thrust mode, clusters of small engines can provide "big engine" performance reducing engine development time and cost. The availability of LUNOX in LLO to "reoxidize" the LANTR enables reusable LTS operations with smaller, less massive LTVs having improved payload carrying capability compared to the "all $\mathrm{LH}_{2}{ }^{n}$ NTR systems. The LANTR can also provide quick "commuter" flights to and from the Moon with "one way" transit times on the order of 36 to 24 hours. The trimodal LANTR concept offers the potential for revolutionizing lunar space transportation and is expected to provide equally exciting prospects for the exploration of Mars and the outer solar system. 


\section{Acknowledgments}

This study was performed within the Advanced Space Analysis Office (ASAO) at NASA's Lewis Research Center (LeRC) in Cleveland, Ohio and at GenCorp Aerojet in Sacramento, California. The authors gratefully acknowledge the programmatic support of their respective organizations and the contributed analysis of Mr. Leon Gefert (LeRC/ASAO) in the area of $\Delta V$ requirements for "quick trip" missions to the Moon. The authors also wish to thank Mr. Pat Rawlings (Science Applications International Corporation in Houston) for the artwork depicted in Figure 10.

\section{References}

Borowski, S. K. (1991) “The Rationale/Benefits of Nuclear Thermal Rocket Propulsion for NASA's Lunar Space Transportation System," AIAA-91-2052, presented at the 27th Joint Propulsion Conference, Sacramento, CA, 24-26 June 1991.

Borowski, S. K., R. R. Corban, D. W. Culver, M. J. Bulman and M. C. Mcllwain (1994) "A Revolutionary Lunar Space Transportation System Architecture Using Extraterrestrial LOX-Augmented NTR Propulsion," AIAA-94-3343, presented at the 30th Joint Propulsion Conference, Indianapolis, IN, $27-29$ June 1994.

Christiansen, E. L., et al. (1988) Conceptual Design of a Lunar Oxygen Pilot Plant, Eagle Engineering Report No. 88-182, Eagle Engineering, Inc., Houston, TX.

Culver, D. W., V. Kolganov, and R. Rochow (1994) "Low Thrust, Deep Throttling, US/CIS Integrated NTRE," in Proc. 11th Symposium on Space Nuclear Power and Propulsion, CONF-940101, M.S. El-Genk, ed., American Institute of Physics, New York, AIP Conference Proc. No. 301, 2: 637-651.

ExPO (1992) Analysis of the Synthesis Group's "Space Resource Utilization" Architecture, XE-29-004, NASA Exploration Program Office, Houston, TX.

Joosten, B. K., and L. A. Guerra (1993) "Early Lunar Resource Utilization: A Key to Human Exploration," AIAA-93-4784, presented at AIAA Space Programs and Technologies Conference, Huntsville, AL, 21-23 September 1993.

NASA (1989) Report of the 90-Day Study on Human Exploration of the Moon and Mars, National Aeronautics and Space Administration, Washington, D. C.

Priest, C. C., and G. R. Woodcock (1990) "Space Transportation Systems Supporting a Lunar Base," AIAA-90-0422, presented at the 28th Aerospace Sciences Meeting, Reno, NV, 8-11 January 1990.

Rutledge, W. S. (1994) "Launch Vehicle Cost Trends," Aerospace America, 32(6): 38-41.

Sullivan, T. S., and D. S. McKay (1991) Using Space Resources, NASA Johnson Space Center, Houston, TX.

Synthesis Group (1991) America at the Threshold--America's Space Exploration Initiative, Report of the Synthesis Group, U. S. Government Printing Office, Washington, D. C. 
Public reporting burden for this collection of information is estimated to average 1 hour per response, including the time for reviewing instructions, searching existing data sources, gathering and maintaining the data needed, and completing and reviewing the collection of information. Send comments regarding this burden estimate or any other aspect of this collection of information, including suggestions for reducing this burden, to Washington Headquarters Services, Directorate for Information Operations and Reports, 1215 Jefferson Davis Highway, Suite 1204, Arlington, VA 22202-4302, and to the Office of Management and Budget, Paperwork Reduction Project (0704-0188), Washington, DC 20503.

\begin{tabular}{|l|l|l}
\hline 1. AGENCY USE ONLY (Leave blank) & $\begin{array}{c}\text { 2. REPORT DATE } \\
\text { October } 1995\end{array}$ & $\begin{array}{r}\text { 3. REPORT TYPE AND DATES COVERED } \\
\text { Technical Memorandum }\end{array}$
\end{tabular}

\section{TITLE AND SUBTITLE}

5. FUNDING NUMBERS

Human Exploration and Settlement of the Moon Using LUNOX-Augmented NTR Propulsion

6. AUTHOR(S)

WU-242-10-01

Stanley K. Borowski, Donald W. Culver, and Melvin J. Bulman

7. PERFORMING ORGANIZATION NAME(S) AND ADDRESS(ES)

8. PERFORMING ORGANIZATION REPORT NUMBER

National Aeronautics and Space Administration

Lewis Research Center

Cleveland, Ohio 44135-3191

E-9971

9. SPONSORING/MONITORING AGENCY NAME(S) AND ADDRESS(ES)

10. SPONSORING/MONITORING AGENCY REPORT NUMBER

National Aeronautics and Space Administration

Washington, D.C. 20546-0001

NASA TM-107093

11. SUPPLEMENTARY NOTES

Prepared for the 12th Symposium on Space Nuclear Power and Propulsion cosponsored by BMDO, NASA, DOE, and USAF, Albuquerque, New Mexico, January 8-12, 1995. Stanley K. Borowski, NASA Lewis Research Center; Donald W. Culver and Melvin J. Bulman, GenCorp Aerojet, P.O. Box 13222, Sacramento, California 95813-6000. Responsible person, Stanley K. Borowski, organization code 6850, (216) 977-7091.

12a. DISTRIBUTIONAVAILABILTTY STATEMENT 12b. DISTRIBUTION CODE

Unclassified -Unlimited

Subject Categories 16 and 20

This publication is available from the NASA Center for Aerospace Information, (301) 621-0390.

13. ABSTRACT (Maximum 200 words)

An innovative trimodal nuclear thermal rocket (NTR) concept is described which combines conventional liquid hydrogen $\left(\mathrm{LH}_{2}\right)$-cooled NTR, Brayton cycle power generation and supersonic combustion ramjet (scramjet) technologies. Known as the liquid oxygen (LOX)augmented NTR (LANTR), this concept utilizes the large divergent section of the NTR nozzle as an "afterburner" into which LOX is injected and supersonically combusted with nuclear preheated hydrogen emerging from the LANTR's choked sonic throat--"scramjet propulsion in reverse." By varying the oxygen-to-hydrogen mixture ratio (MR), the LANTR can operate over a wide range of thrust and specific impulse (Isp) values while the reactor core power level remains relatively constant. As the MR varies from zero to seven, the thrust-to-weight ratio for a 15 thousand pound force (klbf) NTR increases by $440 \%$--from 3 to 13 --while the Isp decreases by only 45\%--from 940 to 515 seconds. This thrust augmentation feature of the LANTR means that "big engine" performance can be obtained using smaller, more affordable, easier to test NTR engines. "Reoxidizing" the bipropellant LANTR system in low lunar orbit (LLO) with high density "lunar-derived" LOX (LUNOX) enables a reusable, reduced size and mass lunar transfer vehicle (LTV) which can be deployed and resupplied using two $66 \mathrm{t}$-class Shuttle-derived launch vehicles. The reusable LANTR can also transport 200 to $300 \%$ more payload on each piloted round trip mission than an expendable "all $\mathrm{LH}_{2}$ " NTR system. As initial outposts grow to eventual lunar settlements and LUNOX production capacity increases, the LANTR concept can also enable a rapid "commuter" shuttle capable of 36 to 24 hour "one way" trips to the Moon and back with reasonable size vehicles and initial mass in low Earth orbit (IMLEO) requirements.

14. SUBJECT TERMS

Nuclear thermal rocket; NTR; LUNOX; Lunar-oxygen; Scramjet cascade injector; LOX afterburner; "24 hour" lunar shuttle; LANTR

15. NUMBER OF PAGES

14

16. PRICE CODE

$\mathrm{A} 03$

17. SECURITY CLASSIFICATION

OF REPORT

Unclassified
OF THIS PAGE

Unclassified
19. SECURITY CLASSIFICATION

Unclassified OF ABSTRACT 